milky yellow fluid was aspirated from the right chest and $90 \mathrm{ml}$ from the left chest. The child subsequently made a good recovery.

\section{Discussion}

Late vascular perforation of central venous cannulae may result in either hydrothorax or tamponade if the superior vena cava or right atrium is perforated. ${ }^{34}$ In the patients described hydrothorax resulted from the infusion fluid collecting in the pleural space. Haemothorax was not observed, presumably because the cannula passes through and then plugs the hole made in the superior vena cava. Correct intravenous positioning was confirmed after insertion of the cannulae and the catheters performed satisfactorily at the time of operation and in the immediate postoperative period. At the time the cannulae were removed, blood could not be aspirated from the cannulae; further evidence that perforation had occurred.

The incidence of this complication may be reduced to a minimum by observing the following precautions. The catheter should be of a soft material and its length proportional to the size of the patient. The right internal jugular vein should be chosen in preference to the left. Correct positioning of the cannula should be confirmed and checked daily by observing free backflow of blood into the distal part of the infusion system when it is lowered below atrial level. Respiratory oscillations should be seen but these may still be present after vascular perforation if the tip of the cannula is within the thorax.

If free backflow of blood is not observed the cannula tip may be against the vessel wall. Central venous pressure measurements made in this position are unlikely to be reliable. The cannula should be repositioned so that blood can be aspirated freely. If this cannot be achieved the cannula should be removed since movement of the cannula tip against the vessel wall may result in devascularisation, erosion, and perforation. Forceful flushing of a poorly functioning central venous pressure line is not recommended. The cannula should be firmly secured to the skin to prevent movement of its tip against the vessel wall.

Cannulation of the superior vena cava via the internal jugular vein has justifiably achieved widespread acceptance in recent years. The need for such lines should be constantly under review and as soon as they have fulfilled their initial usefulness they should be removed. If long term central venous access is required a silastic catheter should be inserted under general anaesthesia with full aseptic technique.

\footnotetext{
References

${ }^{1}$ Rosen M, Latto IP, Ng WS. The internal jugular vein. Handbook of percutaneous central venous catheterisation. London: W B Saunders, 1981:106-12.

${ }^{2}$ English ICW. Internal jugular vein catheterisation. In: Peters $\mathrm{JL}$, ed. A manual of central venous catheterisation and parenteral nutrition. Bristol: John Wright and Sons, 1983: 62-9.

${ }^{3}$ Criado A, Mena A, Figueredo R, Reig E, Avello F. Late perforation of superior vena cava and effusion caused by central venous catheter. Anaesth Intensive Care 1981;9:286-8.

4 Defalque R, Campbell C. Cardiac tamponade from central venous catheters. Anesthesiology 1979;50:249-52.
}

Correspondence (no reprints available) to A M Henderson, 1 Darren Close, London N4 4EF.

Received 27 March 1984

\title{
Intravenous pulse methylprednisolone in chronic idiopathic thrombocytopenia
}

\author{
A MENICHELLI, D DEL PRINCIPE, AND E REZZA \\ Department of Paediatrics, University of Rome, 'La Sapienza', Italy
}

SUMMARY Two children with chronic idiopathic thrombocytopenic purpura unresponsive to either standard corticosteroid treatment or high dose intravenous gammaglobulin, or both, were treated with intravenous methylprednisolone (15 mg/kg/ day) given in pulses over three consecutive days. Both children showed a positive response and are still in remission after three months.
The term chronic idiopathic thrombocytopenic purpura should be considered when a platelet count of below $60 \times 10^{9} / l$ persists for 6 to 12 months or longer. Until now splenectomy has been considered the treatment of choice, ${ }^{1}$ but alternative forms of treatment such as plasmapheresis ${ }^{2}$ and high dose intravenous gammaglobulins ${ }^{3}$ have been proposed in recent years. The successful use of intravenous pulses of methylprednisolone has been reported in a woman with chronic idiopathic thrombocytopenic 
purpura, ${ }^{4}$ and we describe two similarly affected children who recovered after this treatment.

\section{Case reports}

Case 1. This 3 year old child was admitted to hospital in September 1976 because of mucocutaneous haemorrhages; his platelet count was $10 \times 10^{9} / 1$ and antiplatelet antibodies were present. Differential diagnosis enabled us to rule out infectious diseases and lymphoproliferative, hereditary, or autoimmune disorders as a cause for the thrombocytopenia. The child was treated with prednisone $(2 \mathrm{mg} / \mathrm{kg} /$ day for two weeks) as soon as the diagnosis of idiopathic thrombocytopenic purpura was made and the same treatment schedule was repeated 6 months later. Although the platelet count remained constantly low ( 15 to $\left.20 \times 10^{9} / 1\right)$, the patient was asymptomatic, showing petechiae and slight bruises only after trauma. Splenectomy was deferred, initially because of the child's young age and later because of his good general health which enabled him to lead a normal life at home and school (the only restriction was the avoidance of contact sports).

During the sixth year after the onset of idiopathic thrombocytopenic purpura the patient was treated with high dose intravenous gammaglobulin. His platelet count rose to $70 \times 10^{9} / 1$ after the third injection, but within a week it returned to pretreatment values and remained low after the additional injections.

In the seventh year of the disease he was treated with intravenous pulses of methylprednisolone (15 $\mathrm{mg} / \mathrm{kg} / \mathrm{day}$ ) for three consecutive days. His platelet count before and after this treatment is shown in the Figure. The patient is presently maintaining a platelet count of 80 to $90 \times 10^{9} / 1$ after 3 months

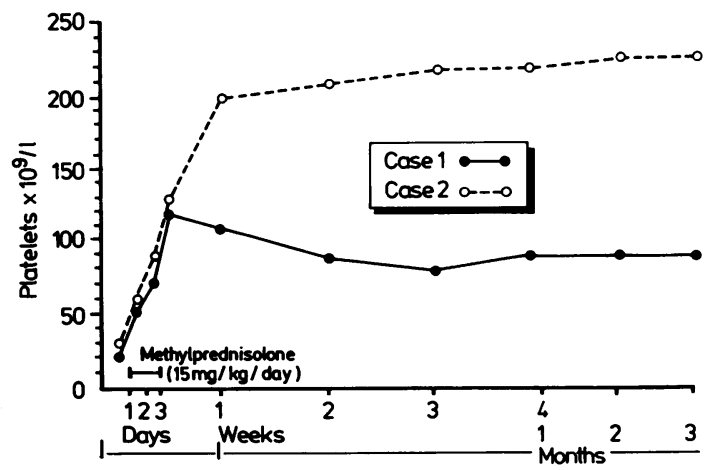

Figure Platelet count during and after methylprednisolone treatment.
Table Platelet aggregation (\%) after treatment with methylprednisolone

\begin{tabular}{lll}
\hline & $\begin{array}{l}\text { Adenosine } \\
\text { diphosphate }\end{array}$ & Collagen $^{*}$ \\
\hline Case 1 & 39 & 60 \\
Case 2 & 50 & 70 \\
Normal range & $35-75$ & $45-96$ \\
\hline
\end{tabular}

*Final concentration $2 \mu \mathrm{m}$.

follow up, and no side effects related to the treatment have been found. Aggregation studies show good platelet function (Table).

Case 2. This 10 year old child was admitted to hospital in October 1983 with chronic idiopathic, thrombocytopenic purpura of one year's duration. His platelet count was $30 \times 10^{9} / 1$. He was in good general health; bleeding manifestations consisted of cutaneous ecchymoses and petechiae. He had not responded to corticosteroid treatment given at the beginning of the disease and treatment with intravenous pulses of methylprednisolone was therefore started $(15 \mathrm{mg} / \mathrm{kg} /$ day for three consecutive days). His platelet count rose to $130 \times 10^{9} / 1$ (Figure; Table), no side effects were detected, and the patient has a platelet count of $220 \times 10^{9} / 1$ after follow up of three months.

\section{Discussion}

These results suggest that methylprednisolone given in pulses is a useful treatment in patients suffering from chronic idiopathic thrombocytopenic purpura. Although the patient in case 1 is still slightly thrombocytopenic, it must be stressed that his platelet counts remained and still are above the danger zone $\left(50 \times 10^{9} / 1\right){ }^{1}$ The lack of toxicity, short duration of treatment, low cost, and the rapid increase in platelet count makes this a safe additional treatment with a good chance of remission before resorting to surgery.

Splenectomy, which has been reported to be the elective treatment for chronic idiopathic thrombocytopenic purpura, has been associated with the development of fatal sepsis, regardless of the age of the patient. Half to one per cent of patients who have undergone splenectomy die of overwhelming infection..$^{5}$ Moreover, autoantibodies may be produced in extrasplenic sites.

Intravenous infusion of high dose gammaglobulin has been followed by sustained rises in the platelet count, ${ }^{3}$ but unfortunately, frequent early relapses occur ( $80 \%$ after four weeks). The treatment is very expensive and even if it is reported to be well 
tolerated, carries the potential risks related to the use of plasma derivative products. The proposed indications for high dose gammaglobulin infusion are (a) when a rapid increase in platelet count is required, (b) as a substitute for immunosuppressive drugs, (c) when steroid treatment is ineffective, and (d) as an attempt to avoid splenectomy. ${ }^{6}$

It is worth considering treatment with pulses of methylprednisolone in children who are unresponsive to standard corticosteroid and high dose intravenous gammaglobulin treatments before considering other therapeutic procedures.

This study was supported by the CNR (grant $83.02571 \cdot 04$ ) and the Ministero Pubblica Sotrusione.

\section{References}

${ }^{1}$ Stuart MJ, McKenna R. Diseases of coagulation: the platelet and vasculature. In: Nathan and Osky, eds. Hematology of infancy and childhood vol II, 2nd ed. Philadelphia, London, Toronto: WB Saunders, 1981:1234-338.

2 Marder VJ, Nusbacher J, Anderson FW. One year follow up of plasma exchange therapy in 14 patients with thrombocytopenic purpura. Transfusion 1981;21:291-8.

3 Inbach P, Barandun S, D'Apuzzo V, et al. High-dose intravenous gammaglobulin for idiopathic thrombocytopenic purpura in childhood. Lancet $1981 ; \mathbf{i}: 1228-31$.

4 Oto A, Sozen T, Ozisik Y. Pulse methylprednisolone therapy in idiopathic thrombocytopenic purpura. Acta Haematol 1983;70:345.

5 Eraklis AJ, Filler RM. Splenectomy in childhood: a review of 1413 cases. $J$ Pediatr Surg 1972;7:382-8.

${ }^{6}$ Mori PG, Mancuso G, Del Principe D, et al. Chronic idiopathic thrombocytopenia treated with immunoglobulin. Arch Dis Child 1983;58:851-5.

Correspondence to Dr A Menichelli, Department of Pediatrics, University of Rome, "La Sapienza", Viale Regina Elena 324, 00161 Rome, Italy.

Received 29 March 1984

\title{
High volume milk feeds for preterm infants
}

\author{
M A LEWIS AND B A M SMITH
}

Nether Edge Hospital, Sheffield

SUMMARY Fifty nine preterm infants of between 1.0 and $2.0 \mathrm{~kg}$ birthweight who were fed $250 \mathrm{ml} / \mathrm{kg} /$ day of breast milk or standard formulas gained weight at the intrauterine rate without complications. It is suggested that high volume feeding is a satisfactory alternative to low birthweight formula milks and is more desirable in infants who are to be breast fed.

Current practice includes the restriction of feed volumes given to preterm infants to between 150 and $200 \mathrm{ml} / \mathrm{kg} /$ day. This has accentuated the difficulty in achieving satisfactory postnatal growth and has led to the development of special low birthweight formulas. ${ }^{1}$ Doubt about the necessity for volume restriction led us to review retrospectively the available data on growth of preterm infants in our unit when feed volumes were not restricted and when only breast milk or a standard formula was used.

\section{Patients and methods}

We reviewed the hospital records of all infants with a birthweight of less than $2.0 \mathrm{~kg}$ born at Nether Edge Hospital, Sheffield during 1976 to 1978 inclusive.
Seven infants weighed less than $1.0 \mathrm{~kg}$ and all died. There were 87 infants with birthweights between 1.0 and $2.0 \mathrm{~kg}: 18$ of these were born at term and are not included in this study. Ten of the remainder died within the first postnatal week (six from respiratory distress syndrome, three from lethal congenital anomalies, and one from severe birth asphyxia). This left 59 preterm infants. Thirty were appropriate for gestational age and 29 were small for gestational age (weight less than the 10th centile). Seventeen infants weighed less than $1.5 \mathrm{~kg}$ (five appropriate and six small for gestational age). Thirteen of the 59 infants had respiratory problems requiring increased inspired oxygen concentrations for more than 48 hours after birth. Several were also given continuous positive airways pressure. Facilities for mechanical ventilation were not available. Several infants received antibiotics for presumed or proved infection and several received theophylline for apnoea.

Infants were breast, bottle, tube, or spoon fed; no transpyloric feeding or parenteral nutrition was used. Volumes of feeds were steadily increased, according to tolerance, until satisfactory weight gain was achieved. When ready to breast feed infants were 'test weighed' and if necessary were complemented with expressed breast milk until two to three days before discharge. Feed charts had been 